\title{
The effect of method of presentation, set, and stimulus dimensions on "same"."different" reaction times*
}

\author{
LARRY R. DECKER† \\ University of Arizona, Tucson, Arizona 85721
}

\begin{abstract}
"Same"-"different" reaction times (RTs) to random shapes varying independently in either brightness, size, or form were studied in an investigation of visual encoding and comparison processes. The comparison process was investigated by having the varying dimension either cued in advance (set) or not cued (no set). The encoding process was investigated by varying stimulus onset asynchronies. No significant difference was found for the set/no-set variables, providing some evidence for an integrality interpretation. However, the serial and parallel models would still hold if the set variable does not affect either dimensional processing rate or order. The significant difference found between the various stimulus onset asynchronies was interpreted as evidence for a limited-capacity encoding mechanism. The results were also consistent with a two-process model of comparison processes.
\end{abstract}

Investigations that require Ss to judge whether stimuli that vary along physical dimensions are "same" or "different" (Egeth, 1966; Hawkins, 1969) have indicated that the stimulus dimensions may be processed by $S$ in at least two basic ways: in serial or in parallel. Processing is said to be serial when a stimulus is analyzed into separate dimensions that are processed in sequence or when the processing of one dimension is dependent upon the completion of the processing of another dimension. Processing is said to be parallel when the processing of dimensions occurs either simultaneously or independently. ${ }^{1}$ In serial processing, comparisons may be in a fixed order (the dimensions are always compared in the same order) or in a random order (the order of dimensional comparisons is a random variable). In parallel processing, comparison times may be either distributed (the time taken to compare a particular dimension is a random variable) or constant (the time taken to compare a particular dimension does not vary). A third possible mode of processing involves a nondimensional approach, where the stimulus is processed as a "whole" and processing is said to be integral (Lockhead, 1966; Garner \& Felfoldy, 1970). Integrality is rather loosely defined, dimensions being considered integral if they cannot exist separately (e.g., a visual stimulus must simultaneously have

*The present study is based on a dissertation submitted to the Department of Psychology, University of Arizona, in partial fulfillment of the requirements of the $\mathrm{PhD}$ degree. The author would like to thank his chairman, Professor Neil R. Bartlett, Terry C. Daniel, member of the committee, and Joan G. Snodgrass and Marcel Kinsbourne for their comments and assistance in the preparation of the manuscript. A version of this paper was presented at the Western Psychological Association Convention, 1973.

†Now at the Department of Psychology, California State College, Dominguez Hills, California. form, size, hue, brightness, saturation, and position in time and space). Integrality thus assumes that nonseparable (integral) dimensions will be processed as one stimulus, while the parallel model assumes a simultaneous, but dimensional, analysis of all stimuli. (For a more complete review of the serial and parallel models and the integrality hypothesis, see Nickerson, 1972.)

Prior to the comparison process, the stimulus information must be encoded. Several investigators have reported that a sequential presentation of stimuli reduces "same"."different" reaction times (RT) as compared to a simultaneous presentation (Nickerson, 1967; Bindra, Donderi, \& Nishisato, 1968; Grill, 1971; Snodgrass, 1972). Snodgrass (1972) offered a tentative explanation of the difference in RTs in simultaneous vs sequential presentation in terms of stimulus encoding time. Snodgrass termed the simultaneous presentation a "discrimination" task and the sequential presentation a "memory" task. She found that the "memory" RTs were faster than the "discrimination" RTs and interpreted that result as indicative of encoding facilitation in the "memory" task. The encoding facilitation effect would seem to indicate a limited-capacity encoding mechanism. In the "memory" task, $S$ is provided with some time (approximately $2 \frac{1}{2} \mathrm{sec}$ of stimulus-on time and $21 / 2 \mathrm{sec}$ of interstimulus interval) to encode the first stimulus before the second is presented. In the "discrimination" task, the stimuli are presented simultaneously, thus apparently overloading the encoding mechanism and increasing the RT.

In the experiment reported here, stimulus encoding capacity and comparison processes were investigated in a "same". "different" RT paradigm. Comparison processes were studied by varying stimuli independently along one of three dimensions and $S$ was either cued as to which dimension might vary or not 
cued. Cuing would affect RT only if it determined either the order in which dimensions were processed (as in the serial models) or the rate of dimensional processing (as in the parallel models). Murdock (1971) has presented some evidence for a parallel-processing model which specifies that the processing rates for items vary with the serial position of those items. Thus, if item processing time can be changed by the order in which items are received, even though they are processed simultaneously, perhaps cuing can change the order of reception (encoding) and thus the rate of dimensional processing. Cuing would not affect RT if processing was done in either an integral manner or if no change in order or rate of dimensional processing time occurred as a result of cuing.

Encoding processes were studied by varying the interval between the onset of the first stimulus $\left(S_{1}\right)$ and the onset of the second stimulus $\left(S_{2}\right)$. If the encoding mechanism was of a limited capacity, then a decrease in RT to $S_{2}$ as the stimulus interval was increased, up to a duration equal to the encoding time of $S_{1}$, would be expected.

\section{METHOD}

\section{Subjects}

Four students, one female and three males, served as paid volunteers. They were paid $\$ 1$ per session plus an extra $50 \mathrm{c}$, which, they were told, was contingent upon low error scores and RTs faster than $600 \mathrm{msec}$.

\section{Apparatus}

An Iconix three-channel tachistoscope was used to present the stimuli. Three light boxes, each with two cold cathode fluorescent lamps, allowed independent exposure of three fields. A slot at the back of each light box accepted $15 \times 28 \mathrm{~cm}$ cards. The actual viewing area was $10 \times 10 \mathrm{~cm}$.

On a table in front of $S$ were two microswitches, labeled "same" and "different," which were connected to an Iconix Model 6255 timebase and counter, which recorded the RT. The microswitches were also connected to two lights which faced $\mathrm{E}$ and indicated which response $S$ had made.

Three colored lights (red, green, and white) were mounted on the front of the viewing box. Presentation of the lights was controlled by E through a control box located behind the viewing box. Above each light was a label indicating "size," "form," or "brightness."

\section{Stimuli}

The stimuli could assume three shapes: all were eight-pointed nonsense figures with approximately equal areal density (judged by superimposing one shape over another) and subjectively dissimilar. ${ }^{2}$ The stimuli were constructed from black construction paper (Munsell reflectance: N2/), gray artist's paper (Munsell reflectance: $\mathrm{N} 5 /$ ), and white mimeo paper (Munsell reflectance: N9.5/). They were mounted on a gray background (Munsell reflectance: $\mathrm{N} 7 /$ ). The stimuli could take on three sizes: 2,4 , or $6 \mathrm{~cm}$ on both the vertical and horizontal planes. They were viewed within four fixation lines, $5 \mathrm{~cm}$ long and arranged in a square. The pairs of stimuli were presented horizontally on the S's right and left and were separated by $.5 \mathrm{~cm}$. Thus, the total display visual angle at the largest stimulus size subtended $6.5 \mathrm{deg}$.

The factorial combination of three forms, three sizes, and three levels of brightness produced 27 different stimuli and 729 possible pairs, 27 "same" and 702 "different."

\section{Procedure}

Ss were tested for uncorrected 20-20 vision by means of a Snellen eye chart. Tape-recorded instructions were then given for the first practice session, in which letters, rather than nonsense shapes, were used as stimuli. That session consisted of 30 presentations of the stimuli, AA, BB, and AB. After the first session, Ss were given final tape-recorded instructions. All of the 27 stimuli were then shown to $S$, and 54 practice trials (the second practice session) were run. During the second session, $S$ s were requested to initiate the trial by pressing a foot pedal located under the table. The $S$ was signaled that the trial was ready to begin by the presentation of one or all of the colored lights.

After the second practice session, the experimental trials were begun. The stimuli were presented in blocks of 20 trials, 10 "same" and 10 "different," with the order of "different" and "same" randomized. Each block within the set condition varied in only one dimension. For example, only brightness might be varied within one block of 20 trials. However. in the no-set condition, the three dimensions were randomly varied within one block of trials.

The set condition was defined by the presentation of only one colored light, and the no-set condition by the presentation of all of the colored lights simultaneously.

Both $S_{1}$ and $S_{2}$ had constant on times of $100 \mathrm{msec}$. There were six different stimulus onset asynchronies (SOA). The SOA values were: $0,50,100,150,200$, and $300 \mathrm{msec}$, and they refer to the time between the onset of $S_{1}$ and the onset of $S_{2}$. The SOAs were presented in an ascending and descending order, counterbalanced over Ss.

The order of events in the second session and in the experimental sessions was: (1) the presentation of the light(s), (2) the press of the foot pedal by $S$, (3) a 500-msec delay, (4) presentation of the stimuli, and (5) S's response. The $S$ responded either "same" or "different" to the stimuli by pressing the appropriate microswitch. During the intertrial interval $(10-15 \mathrm{sec}), \mathrm{S}$ was informed as to whether his response was correct or incorrect.

Each SOA was presented for 120 trials, the set and no-set conditions within each SOA consisted of 60 trials, and each dimensional variable within each set or no-set condition consisted of 20 trials, for a total of 720 trials per $S$. The fixation field was preset continuously, in order to minimize afterimages. The order of presentation of $S_{1}$ was constant from right to left in all of the SOAs except, of course, the 0 SOA.

Half of the Ss used the dominant hand to respond "same." and the other half used the dominant hand to respond "different."

\section{RESULTS AND DISCUSSION}

Table 1 presents mean "same" and "different" RTs for each SOA, each set and no-set condition, and each S. Only correct RTs were used in the analyses. The error rate appears at the bottom of the table and is based upon a total of 120 responses. The overall error rate of $4.4 \%$ (based on 720 responses) is relatively low. A one-way ANOVA on the arcsine transformed error percentages indicates that the frequency of errors in each SOA are not significantly different $[F(5,3)=5.93]$. However, the 300 SOA has the highest error percentage $(6.1 \%)$.

Figures 1 and 2 present the major results of the experiment. These graphs illustrate the lack of an overall set/no-set effect. "Same" RTs (set) show a consistent drop from the 0 SOA to the 50 SOA, where they make a slight rise at 100 (which is regarded as artifactual due to the consistency of the other data), and then drop again to the lowest level at 150 . The 
Table 1

Mean "Same" and "Different" Correct RTs (in Milliseconds) for Set and No-Set Conditions Within Each Stimulus Onset Asynchrony

\begin{tabular}{|c|c|c|c|c|c|c|c|c|}
\hline \multirow[b]{3}{*}{$S$} & \multicolumn{4}{|c|}{0} & \multicolumn{4}{|c|}{50} \\
\hline & \multicolumn{2}{|c|}{ Set } & \multicolumn{2}{|c|}{ No Set } & \multicolumn{2}{|c|}{ Set } & \multicolumn{2}{|c|}{ No Set } \\
\hline & Same & Diff & Same & Diff & Same & Diff & Same & Diff \\
\hline $\begin{array}{l}1 \\
2 \\
3 \\
4\end{array}$ & $\begin{array}{l}603 \\
414 \\
549 \\
415\end{array}$ & $\begin{array}{l}628 \\
495 \\
529 \\
458\end{array}$ & $\begin{array}{l}509 \\
463 \\
678 \\
420\end{array}$ & $\begin{array}{l}543 \\
517 \\
748 \\
428\end{array}$ & $\begin{array}{l}440 \\
433 \\
488 \\
371\end{array}$ & $\begin{array}{l}455 \\
462 \\
436 \\
447\end{array}$ & $\begin{array}{l}414 \\
416 \\
555 \\
472\end{array}$ & $\begin{array}{l}460 \\
507 \\
487 \\
515\end{array}$ \\
\hline $\begin{array}{c}\text { Mean } \\
\text { PE }\end{array}$ & $\begin{array}{r}495 \\
4.1\end{array}$ & $\begin{array}{r}528 \\
3.3\end{array}$ & $\begin{array}{r}516 \\
3.3\end{array}$ & $\begin{array}{r}559 \\
6.6\end{array}$ & $\begin{array}{r}433 \\
6.6\end{array}$ & $\begin{array}{r}450 \\
3.3\end{array}$ & $\begin{array}{r}464 \\
4.1\end{array}$ & $\begin{array}{r}492 \\
3.3\end{array}$ \\
\hline PE & \multicolumn{4}{|c|}{100} & \multicolumn{4}{|c|}{150} \\
\hline $\begin{array}{l}1 \\
2 \\
3 \\
4\end{array}$ & $\begin{array}{l}439 \\
382 \\
524 \\
442\end{array}$ & $\begin{array}{l}427 \\
441 \\
452 \\
425\end{array}$ & $\begin{array}{l}409 \\
411 \\
417 \\
439\end{array}$ & $\begin{array}{l}387 \\
480 \\
462 \\
427\end{array}$ & $\begin{array}{l}386 \\
349 \\
426 \\
397\end{array}$ & $\begin{array}{l}410 \\
405 \\
461 \\
418\end{array}$ & $\begin{array}{l}364 \\
375 \\
461 \\
401\end{array}$ & $\begin{array}{l}388 \\
440 \\
449 \\
433\end{array}$ \\
\hline \multirow[t]{2}{*}{$\mathrm{PE}$} & $\begin{array}{r}447 \\
6.6\end{array}$ & $\begin{array}{r}436 \\
2.5\end{array}$ & $\begin{array}{r}419 \\
3.3\end{array}$ & $\begin{array}{r}439 \\
3.3\end{array}$ & $\begin{array}{r}390 \\
2.5\end{array}$ & $\begin{array}{r}424 \\
4.1\end{array}$ & $\begin{array}{r}400 \\
2.5\end{array}$ & $\begin{array}{r}428 \\
6.6\end{array}$ \\
\hline & \multicolumn{4}{|c|}{200} & \multicolumn{4}{|c|}{300} \\
\hline $\begin{array}{l}1 \\
2 \\
3 \\
4\end{array}$ & $\begin{array}{l}387 \\
356 \\
501 \\
372\end{array}$ & $\begin{array}{l}403 \\
400 \\
495 \\
416\end{array}$ & $\begin{array}{l}367 \\
435 \\
448 \\
374\end{array}$ & $\begin{array}{l}409 \\
455 \\
460 \\
522\end{array}$ & $\begin{array}{l}424 \\
390 \\
414 \\
486\end{array}$ & $\begin{array}{l}476 \\
431 \\
460 \\
516\end{array}$ & $\begin{array}{l}430 \\
482 \\
419 \\
402\end{array}$ & $\begin{array}{l}458 \\
557 \\
405 \\
440\end{array}$ \\
\hline $\begin{array}{c}\text { Mean } \\
\text { PE }\end{array}$ & $\begin{array}{r}404 \\
4.1\end{array}$ & $\begin{array}{r}404 \\
3.3\end{array}$ & $\begin{array}{r}406 \\
4.1\end{array}$ & $\begin{array}{r}462 \\
2.5\end{array}$ & $\begin{array}{r}428 \\
6.6\end{array}$ & $\begin{array}{r}471 \\
9.1\end{array}$ & $\begin{array}{r}433 \\
6.6 \\
\end{array}$ & $\begin{array}{r}465 \\
4.1 \\
\end{array}$ \\
\hline
\end{tabular}

Note-Means for each $S$ are based on 22 responses. $P E=$ percent error.

latency of "same" RTs increases again at the 200 level, and continues to rise at the 300 level. The "same" (no-set) RTs and the "different" RTs (set and no-set) all show the same U-shaped function without the slight rise at the 100 SOA. "Same" RTs are also shorter (approximately $30 \mathrm{msec}$ on the average) than "different" RTs.

A four-way repeated measures analysis of variance has as one factor each: SOAs, set (set vs no set), dimensions (brightness, form, and size), and response type ("same" vs "different"). The results of the ANOVA are presented in Table 2.

The significant SOA effect was further explored with Duncan's multiple range test. The results of that post hoc test are presented in Table 3 .

One possible explanation of the SOA effect is in terms of viewing $S_{1}$ as a warning signal for $S_{2}$. Bertelson (1967), Posner and Boies (1971), and Colegate, Hoffman, and Eriksen (1973) have shown that RT is reduced if a warning precedes the signal to respond by an interval of some $100-500 \mathrm{msec}$. The present study found the shortest RTs when $S_{1}$ preceded $S_{2}$ by only $50 \mathrm{msec}$ and an increase in RT when the interval was lengthened to $100 \mathrm{msec}$. It appears difficult to reconcile the "warning signal" interpretation with the increase in $\mathrm{RT}$ as the SOA increased after 150 . In addition, the Colegate et al (1973) study discussed the problem of determining what the "true warning signal" may have been (i.e., in

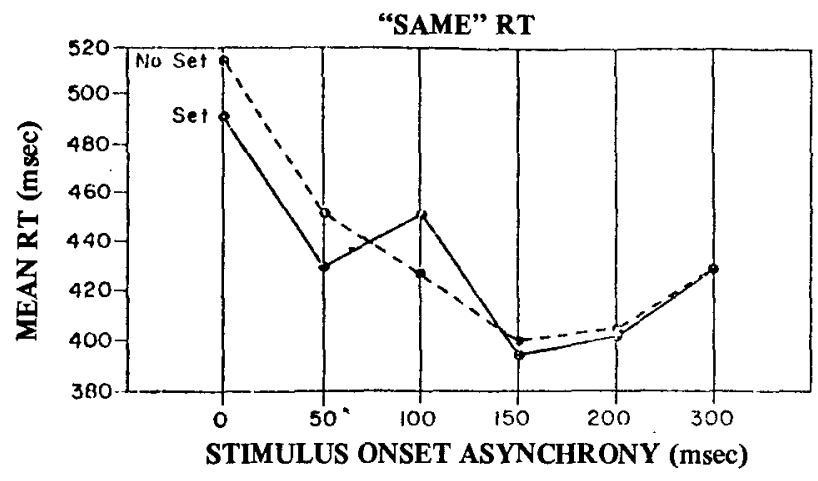

Fig. 1. The interaction of stimulus onset asynchronies, set/no-set, and "same" RT.

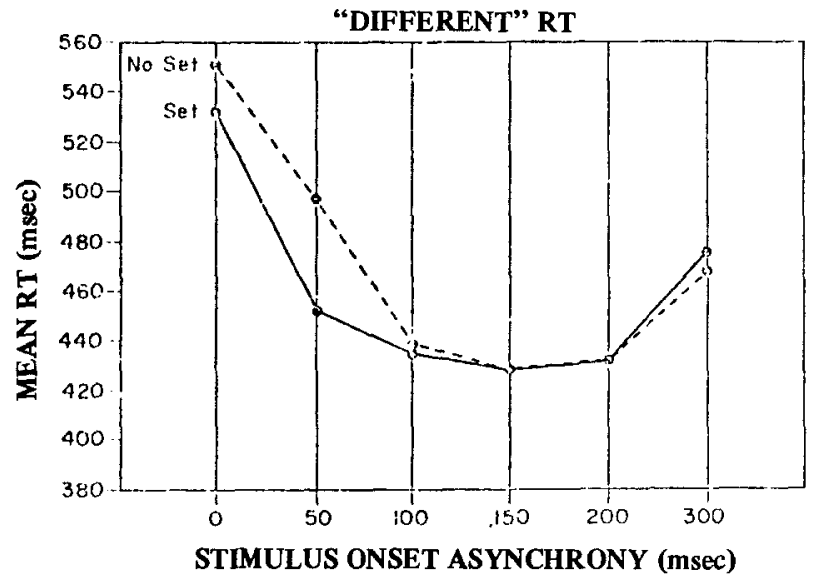

Fig. 2. The interaction of stimuus onset asynchronies, set/no-set, and "different" RT.

Table 2

Summary of Analysis of Variance on Mean Correct RTs $\dagger$

\begin{tabular}{lcc}
\hline Source of Variation & df & F \\
\hline Stimulus Onset Asynchrony (A) & 5,36 & $36.9^{* * *}$ \\
Set/No Set (S) & 1,12 & 1.2 \\
Dimensions (D) & 2,18 & $5.6^{*}$ \\
Response (R) & 1,12 & $17.3^{* *}$ \\
A by S & 5,36 & 1.6 \\
A by D & 10,66 & $3.0^{* *}$ \\
A by R & 5,36 & $82.1^{* *}$ \\
S by D & 2,18 & 3.0 \\
S by R & 1,12 & $<1$ \\
D by R & 2,12 & $<1$ \\
A by S by D & 10,66 & $<1$ \\
A by S by R & 5,30 & $<1$ \\
A by D by R & 10,66 & $<1$ \\
S by D by R & 2,18 & $<1$ \\
A by S by D by R & 10,66 & 1.2 \\
\hline
\end{tabular}

IIn all cases the error term is the interaction of the factor with Ss. ${ }^{*} p<.025 \quad * *<.01 \quad * * *<.001$ 
Table 3

Result of Multiple Range Test

\begin{tabular}{lcccccc}
\hline & \multicolumn{6}{c}{ Stimulus Onset Asynchrony } \\
\cline { 2 - 7 } & 0 & 50 & 300 & 100 & 200 & 150 \\
\hline "Same" RT Means & 503 & 442 & 430 & 441 & 405 & 395 \\
"Diff" RT Means & 542 & 472 & 464 & 436 & 432 & 428 \\
\hline
\end{tabular}

the present study, the presentation of the lights, the $S$ pressing the foot pedal, and presentation of $S_{1}$ may all be viewed as "warning signals").

An alternative explanation is that of the limited-capacity model of encoding. That is, the gradual decrease in RT demonstrated from the 0 SOA to the 150 SOA may be taken as evidence that two stimuli overload the encoding mechanism. However, the increase in RT after the 150 SOA indicates that, after a particular amount of time $(150 \mathrm{msec})$, encoding is no longer facilitated by a separation of stimuli when a decision must be made regarding the "sameness" of those stimuli. This optimum interval occurs while $S_{1}$ is apparently in the icon (Sperling, 1967). If the encoding mechanism's product is the icon, it may be that iconic comparisons have a direct route to the decision mechanism, by passing any other mechanisms involved when both stimuli are present but neither in the form of the icon. However, this "short-circuiting" with iconic comparisons does not explain the gradual drop in RTs. Thus, a more valid explanation appears to be that the encoding mechanism is limited in terms of its capacity and its speed in processing information. That capacity is exceeded by two stimuli. The increase of RT after the 150 SOA is probably due to S's attempt to maintain a fading image, encode $S_{2}$, and compare the two stimuli. The larger error percentages in the 300 SOA provides more evidence for this interpretation. This limited capacity interpretation is in line with other views of man as an information processor with limitations (see Kerr, 1973, for a rev'ew of those models). However, Shiffrin and Gardner's (1972) finding of no significant difference between a sequential and a simultaneous presentation of a visual letter-detection task led them to conclude that encoding of several spatially distinct stimuli was conducted simultaneously.

Several differences are immediately apparent between Shiffrin and Gardner's (1972) study and the present one. The present study used nonsense shapes rather than letters, used a "same"-"different" task rather than a detection task, and used a greater number of intervals in the sequential presentations. The last difference may be the critical variable accounting for the opposite findings in the two studies. That is, in Experiments 1 and 2, Shiffrin and Gardner used SOAs of $50 \mathrm{msec}$ only. As Figs. 1 and 2 of the present study illustrate, it is unlikely that any significant difference would be found with that small an interval. In Experiment 3 of the previous study, the authors used a 500-msec interval. If the upward trend in RTs, as indicated by the 300 SOA in the present study, continues (as Shiffrin and Gardner's findings indicate that it will), then again it is not surprising that no significant difference resulted between a simultaneous and a sequential presentation.

The lack of a significant set/no-set effect in the present study may be explained as due possibly to the nonseparability (integrality) of the stimulus dimensions within the comparison mechanism. Another criterion for the existence of integrality has been a "redundancy gain in speed" (Garner \& Felfoldy, 1970 ). This redundancy gain would seem to imply that there should not be a significant difference in the processing speeds of integral dimensions. While there does exist a difference in dimensional processing in the present study, the significance is small. Furthermore, there has been some evidence reported that tends to cast doubt on the redundancy gain as a valid criterion for integrality (Saraga \& Shallice, 1973). The lack of a significant Dimension by Set interaction tends to reduce the validity of either a serial or a parallel model interpretation. Of course, if set does not change the order or speed of dimensional processing, those models would still hold.

The significant difference between "same" and "different" RTs may be explained by several two-process models (Bamber, 1969; Tversky, 1969; Krueger, 1970). The shortness of the "same" RT is usually taken as evidence for a fast identity reporter that processes stimuli in a wholistic or integral manner. The relatively longer "different" RT is taken as evidence that "different" judgments are processed by a slower serial processor. Perhaps a- more parsimonious explanation might be that the "normal" way of processing by the comparison mechanism is in an integral manner for stimuli which possess nonseparable dimensions. However, when those dimensions differ, the mechanism must separate the dimensions, which adds a certain amount of time to the comparison process and thus increases "different" RTs. Only further research, which compares discrimination RTs to stimuli with separable dimensions with discrimination RTs to stimuli with nonseparable dimensions, will be able to adequately explain the apparently consistent difference between "same" and "different" RTs.

Finally, it appears that the encoding mechanism is of a limited capacity, with an optimum interval of $150 \mathrm{msec}$ in the separation of the stimuli, making iconic comparisons the fastest means of discrimination. The comparison mechanism may operate on a "normal" basis in an integral manner, but when faced with differences in nonseparable dimensions is forced into a slower comparison process due to the varying of integral dimensions. 


\section{REFERENCES}

BAMBER, D. Reaction times and error rates for "same"-"different" judgments of multidimensional stimuli. Perception \& Psychophysics, 1969, 6, 169-174.

BERTELSON, P. The time course of preparation. Quarterly Journal of Experimental Psychology, 1967, 19. 272-279.

Bindra, D., Donderi, D., \& Nishisato, S. Decision latencies of "same" and "different" judgments. Perception \& Psychophysics, 1968, 3, 121-130.

Colegate, R. L., Hoffman, J. E., \& Eriksen, C. W. Selective encoding from multidimensional visual displays. Perception \& Psychophysics, 1973, 14, 217-224.

Downing, B. D., \& Gossman, J. R. Parallel processing of multidimensional stimuli. Perception \& Psychophysics, 1970, 8, 57-60.

EGETH, H. E. Parallel versus serial processes in multidimensional stimulus discrimination. Perception \& Psychophysics, 1966, 1, 245-252.

GARNER, W. R., \& FELFoldy, G. L. Integrality of stimulus dimensions in various types of information processing. Cognitive Psychology. 1970, 1, 225-241.

GriLl, D. Variables influencing the mode of processing of complex stimuli. Perception \& Psychophysics, 1971, 10, 51-57.

Hawkins, H. L. Parallel processing in complex visual discriminations. Perception \& Psychophysics, 1969, 5, 56-64.

KERR, B. Processing demands during mental operations. Memory \& Cognition, 1973, 1, 401-411.

KRUEGER, L. E. Effects of bracketing lines on speed of "same". "different" judgments of two adjacent letters. Journal of Experimental Psychology, 1970, 84, 324-330.

LockHEAD, G. R. The effects of dimensional redundancy on visual discrimination. Journal of Experimental Psychology, 1966, 72, 95-104.

MuRdock, B. B. A parallel processing model for scanning. Perception \& Psychophysics, 1971, 10, 289-191.
Nickerson, R. S. "Same"-"different" response times with multiattribute stimulus differences. Perceptual \& Motor Skills, 1967. 24. 543-554.

Nickerson, R. S. Binary-classification reaction time: A review of some studies of human information-processing capabilities. Psychonomic Monograph Supplements, 1972, 4, 1-318.

Posner, M. I., \& Boies, S. J. Components of attention. Psychological Review. 1971, 78, 391-408.

Saraga, E., \& Shallice, T. Parallel processing of the attributes of single stimuli. Perception \& Psychophysics, 1973, 13, 261-270.

Shiffrin, R. M., \& Gardner, G. T. Visual processing capacity and attentional control. Journal of Experimental Psychology, $1972,93,71.82$.

SNodgrass, J. G. Matching patterns vs matching digits: The effect of memory dependence and complexity on "same"." different" reaction times. Perception \& Psychophysics. 1972, 11, 341-349.

SPERLiNG, G. Successive approximations to a model for short-term memory. Acta Psychologica, 1967, 27, 285-292.

TVERSKY, B. Pictorial and verbal encoding in a short-term memory task. Perception \& Psychophysics, 1969, 6, 225-233.

\section{NOTES}

1. The use of independence and dependence as synonyms for parallel and serial may not be justified, as there is some evidence that processing may be parallel without being independent (Downing \& Gossman, 1970).

2. The shapes were generated by a computer program developed by Terry C. Daniel, Department of Psychology, University of Arizona, Tucson, Arizona.

(Received for publication January 11, 1974; revision received April 25, 1974.) 